\title{
150 年来若尔盖泥炭沉积支链四醚膜类脂及古环境重建
}

\author{
周浩达 ${ }^{(12)}$, 胡建芳 ${ }^{(1 *}$, 明荔莉 ${ }^{(12)}$, 彭平安 ${ }^{(1)}$, 张千 ${ }^{(1)}$ \\ (1) 中国科学院广州地球化学研究所, 广州 510640; \\ (2) 中国科学院研究生院, 北京 100049 \\ *联系人, E-mail: hujf@gig.ac.cn \\ 2010-11-30 收稿, 2011-04-06 接受 \\ 中国科学院知识创新工程重要方向项目(KZCXZ-YW-JC103)和中国科学院广州地球化学研究所人才基金(GIGRC-09-02)资助
}

\begin{abstract}
摘要 环化指数(CBT)/甲基化指数(MBT)是近年来根据支链四醚膜类脂(GDGTs)提出的定量化 重建土壤 $\mathrm{pH}$ 和陆地年平均大气温度(MAAT)的生物标志物指标. 本文通过对高寒若尔盖草原 泥炭柱状样中 GDGTs 含量的测定, 利用 CBT/MBT 指标定量化重建了其近 150 年来的泥炭 $\mathrm{pH}$ 和 MAAT 的变化. 近 150 年来四川若尔盖草原泥炭 $\mathrm{pH}$ 和 MAAT 大致经历了 3 个变化阶段: 1851 1927 年 $\mathrm{pH}$ 基本没有变化, MAAT 缓慢降低 $1^{\circ} \mathrm{C} ; 1927$ 1979 年 $\mathrm{pH}$ 快速降低 0.6 , MAAT 大幅降低 $2.5^{\circ} \mathrm{C}$; 自 1979 年以来 $\mathrm{pH}$ 和 MAAT 大幅升高 0.8 和 $5^{\circ} \mathrm{C}$. 计算温度与当地气象站记 录的近 45 年来年平均温度具有相似的升温趋势和平均值, 并且近 150 年来计算的 MAAT 和在 该地区利用树木年轮计算的温度具有相似的变化趋势, 表明泥炭沉积中 GDGTs 相关指标在高 分辨重建陆地古环境的适用性和应用潜力。
\end{abstract}

\section{关键词}

泥炭 若尔盖草原 古气候 GDGTs
重建古气候、古环境是为了认识地球系统环境的 变化过程与机制, 从而为预测未来气候环境提供基 础资料, 有效地减少预测中的不确定性. 国内外古气 候学者力图通过冰芯、黄土、树轮、珊瑚、海洋和湖 泊沉积物等不同的研究对象, 获得定量的古气候要 素信息. 在不同研究对象中, 建立历史时期气候环境 高分辨率序列的关键是寻找敏感的气候环境代用指 标, 并利用有效的数理方法定量分离、提取气候环境 信息. 泥炭沉积与冰岩芯、树木年轮、海洋和湖泊沉 积物等一样是重要的地质档案, 而且泥炭主要是本 地生长的植物残体的原地堆积, 埋藏过程相对简单, 沉积有机质含量相对较高, 是利用分子有机地球化 学研究古环境/古气候的良好载体.

泥炭沉积的类脂化合物 (正构烷烃、脂肪醇、脂 肪酸、甾酮、三萜类化合物和类异戊二烯、直链酯类 等)、纤维素 $\mathrm{C}, \mathrm{H}, \mathrm{O}$ 同位素, 以及泥炭腐殖化度和狍 粉生物化石等都是恢复古环境的良好指标 ${ }^{[1 \sim 8]}$. 虽然 泥炭的这些气候代用指标能够反演古环境的相对干
湿、冷暖, 但并不能定量地给出温度值的大小; 而且 很多代用指标在古气候研究中的真正指示意义或与 环境因子(温度、降水、 $\mathrm{CO}_{2}$ 分压等)的相关性尚不明 确, 还需要大量工作去完善.

新近发展的与支链四醚膜类脂 (GDGTs) 类化合 物相关的指标一甲基化指数(MBT, the Methylation index of Branched Tetraethers)和环化指数(CBT, the Cyclisation ratio of Branched Tetraethers)被古气候学 者广泛关注 ${ }^{[9 \sim 12]}$. 目前研究较多的 GDGTs 化合物主 要包括类异戊二烯类 (GDGT-0 GDGT-4 和 Crenarchaeol) 和支链类(I III)两大类, 其分子结构如 图 1 所示. 类异戊二烯 GDGTs 被认为是古菌细胞质 膜中所特有, 是古菌存在的生物标志化合物 ${ }^{[13]}$. 支 链 GDGTs 的来源目前还没有定论, 普遍认为主要来 源于陆地土壤和泥炭中的细菌 ${ }^{[14]}$. Weijers 等人 ${ }^{[9]}$ 通 过对全球 90 个地区 134 个土壤样品中支链 GDGTs 的含量分布与当地环境因子(温度、 $\mathrm{pH}$ 等)的关系研 究, 发现支链 GDGTs 结构中甲基个数(MBT 指数)主

英文版见: Zhou H D, Hu J F, Ming L L, et al. Branched glycerol dialkyl glycerol tetraethers and paleoenvironmental reconstruction in Zoigê peat sediments during the last 150 years. Chinese Sci Bull, 2011, 56, doi: 10.1007/s11434-011-4594-9 
要受当地年平均大气温度(MAAT)影响, 其次受环境 $\mathrm{pH}$ 影响; 支链 GDGTs 结构中环戊烷个数(CBT 指数) 主要受环境 $\mathrm{pH}$ 控制.

Sinninghe Damsté 等人 ${ }^{[10]}$ 利用 MBT/CBT 指标计 算的不同海拔高度的 MAAT 值都比实测温度稍高, 但和实测温度一样, 都随着海拔高度的增加逐渐降 低, 表明了这一陆地古温标的适用性. Peterse 等人 ${ }^{[12]}$ 通过对加利福尼亚州的 2 处热泉周围土壤的研究发 现, CBT 指数和土壤 $\mathrm{pH}$ 有很好的相关性 $\left(R^{2}=0.76\right)$, 由 MBT 指数计算的温度和实测温度也具有良好的相 关性 $\left(R^{2}=0.65\right)$, 再次验证了环境温度是这一陆地古 温标的主要制约因素. 基于 MBT/CBT 的 MAAT 和 $\mathrm{pH}$ 重建已经得到了广泛的应用. 如 Weijers 等人 ${ }^{[15]}$ 通过对刚果河口地区沉积钻孔中 GDGTs 的研究, 重 建了 25000 年来非洲的古气候; Weijers 等人 ${ }^{[16]}$ 利用 MBT/CBT 指数重建了古新世-始新世最暖事件时期 北极大陆的古气温; Schouten 等人 ${ }^{[11]}$ 重建了晚始新世 和早渐新世时期格陵兰岛的古气温; Peterse 等人 ${ }^{[17]}$ 将 MBT/CBT 指数应用于平均温度低于 $0^{\circ} \mathrm{C}$ 的高纬度 地区, 尽管支链 GDGTs 在此地区的含量较低, 但推 算出的温度 $\left(-4^{\circ} \mathrm{C}\right)$ 接近实际温度 $\left(-6^{\circ} \mathrm{C}\right)$.

本研究通过对高寒若尔盖草原泥炭柱状样中
GDGTs 含量的测定, 计算了 CBT 和 MBT 指数, 定量 化地重建了近 150 年来若尔盖地区 MAAT 和泥炭 $\mathrm{pH}$, 为应用 GDGTs 相关指标重建陆地古环境研究提供一 些探索性的资料. 本研究中 CBT 和 MBT 计算精确度 分别为 0.014 和 0.008 , 换算为 $\mathrm{pH}$ 和 MAAT 分别为 \pm 0.04 和 $\pm 0.3^{\circ} \mathrm{C}$.

\section{1 样品采集和处理方法}

\section{1 样品采集及定年}

红原泥炭位于青藏高原东部边缘, 四川省西北 部、阿坝藏族芫族自治州中部, 地处中国最大的高原 泥炭沼泽一一若尔盖泥炭积聚区, 属亚高山草甸草 原带, 属草本泥炭 ${ }^{[18,19]}$. 红原地区属于大陆性高原寒 温带季风型气候, 春秋时间短、长冬无夏, 区内年平 均气温 $0.6 \sim 1.2^{\circ} \mathrm{C}$, 年平均降水量为 $560 \sim 860 \mathrm{~mm}$, 昼 夜温差大, 雨量充足, 雨热同期 ${ }^{[19,20]}$.

研究样品于 2006 年 5 月采自四川红原县高寒湿 地若尔盖草原泥炭区, 采样点位于红原县城西 $2 \mathrm{~km}$ 处 $\left(32^{\circ} 46^{\prime} \mathrm{N}, 102^{\circ} 30^{\prime} \mathrm{E}\right)$, 海拔高度 $3510 \mathrm{~m}$. 采样装置 为不锈钢 Wardenaar 采样器, 柱长 $25 \mathrm{~cm}$. 采取的柱 状样整体置于 PVC 管中, 迅速运至实验室 $-10^{\circ} \mathrm{C}$ 条件

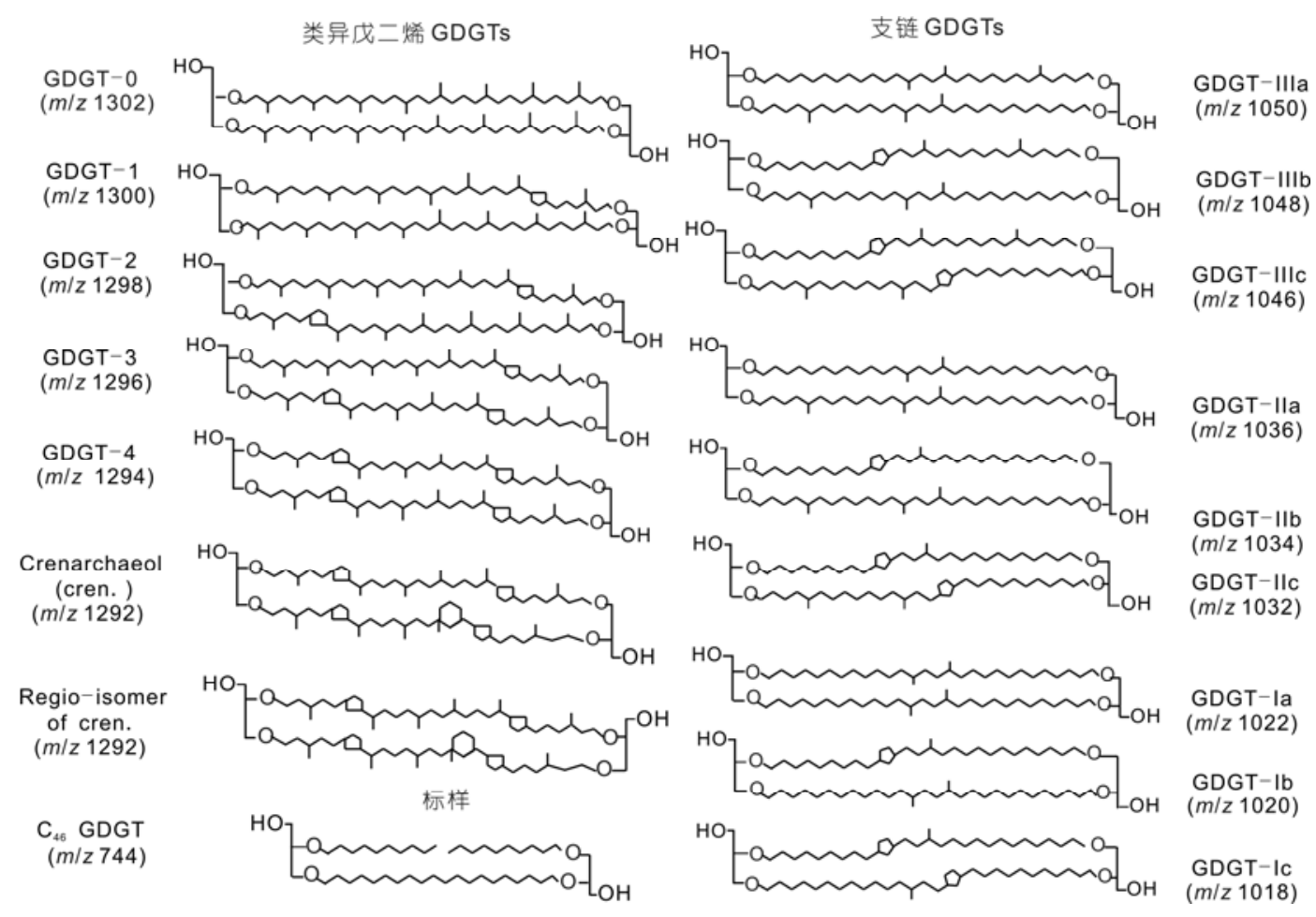

图 1 类异戊二烯类和支链类 GDGTs 分子结构图 
下保存. 纵向分出一部分柱状样用于 ${ }^{210} \mathrm{~Pb}$ 定年, 其 余柱状样以 $0.5 \mathrm{~cm}$ 分样进行 GDGTs 分析.

${ }^{210} \mathrm{~Pb}$ 测年在中国科学院南京地理与湖泊研究所 完成, 柱状样过剩 ${ }^{210} \mathrm{~Pb}\left({ }^{210} \mathrm{~Pb}_{\text {uns }}\right.$ ) (uns, unsupported)剖 面变化如图 2 所示. 计算采用 CIC 模式 ${ }^{[21 ~ 24]}$. 计算得 到泥炭柱的沉积速率为 $0.16 \mathrm{~cm} / \mathrm{a}$, 柱状样定年跨度 为 1851 2006 年.

\section{2 实验方法}

(i ) 样品前处理. 称取适量样品, 加人适量 $\mathrm{C}_{46}$-GDGT 标准化合物(标样, 见图 1), 以甲醇/二氯 甲烷 $(1 / 2, v / v)$ 索氏抽提 $72 \mathrm{~h}$, 得到总类脂抽提物. 对总类脂抽提物进行氧化铝色谱柱分离, 依次用正 己烷/二氯甲烷 $(9 / 1, v / \mathrm{v})$ 、二氯甲烷/甲醇 $(1 / 1, v / v)$ 混 合溶液淋洗, 得到 2 个组分. 将第 2 个组分在氮气下 吹干，重新溶于正已烷/正丙醇(99/1，v/v)中，超声 15 min, 取上清液用 $0.45 \mu \mathrm{m}$ 微孔滤膜进行过滤, 滤液 浓缩后采用高效液相色谱-质谱 (HPLC-MS) 进行 GDGTs 分析.

(ii) 仪器分析. GDGTs 分析仪器采用安捷伦 6410 QQQ HPLC/MS, 分析方法在 Hopmans 等人 ${ }^{[25]}$ 的基础上加以改进 ${ }^{[26]}$. (1) 色谱条件. 色谱柱: 正相

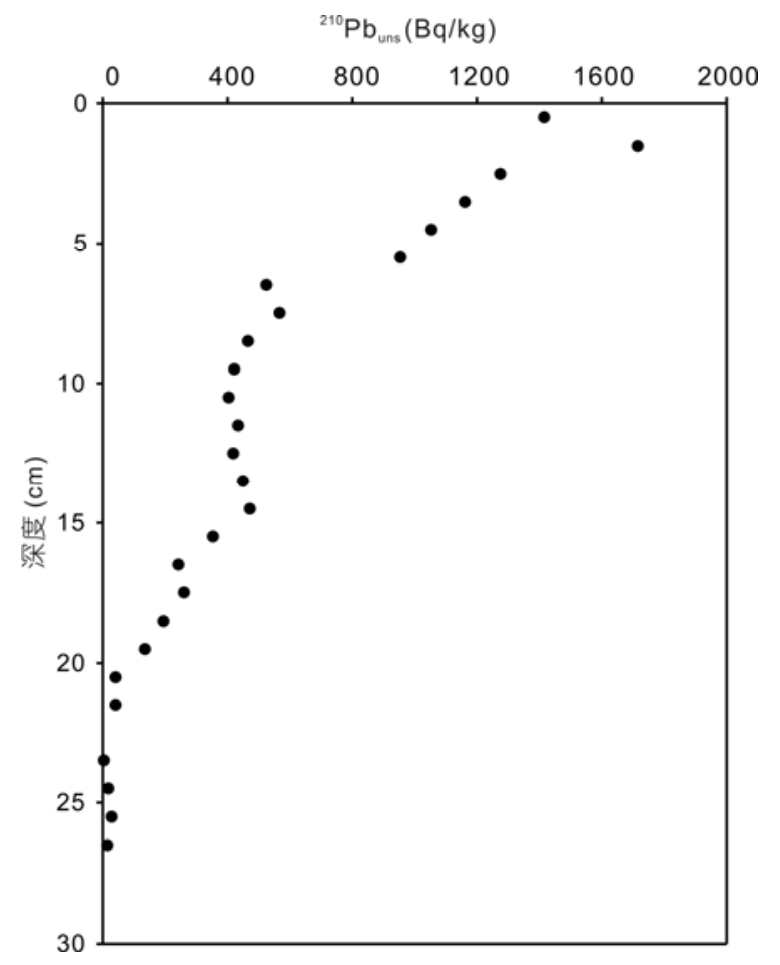

图 2 若尔盖泥炭 ${ }^{210} \mathrm{~Pb}_{\mathrm{uns}}$ 剖面
氰基柱 $(2.1 \mathrm{~mm} \times 150 \mathrm{~mm}, 3 \mu \mathrm{m}$; Alltech, USA), 柱温 $30^{\circ} \mathrm{C}$. 流动相: $\mathrm{A}$ 相-正己烷, $\mathrm{B}$ 相-正丙醇, 在分析初 始 0 5 min 内, 流动相保持为 $99 \% \mathrm{~A}: 1 \% \mathrm{~B}$, 在 5 45 $\min$ 内, 线性变化至 $2 \% \mathrm{~B}$, 流速为 $0.2 \mathrm{~mL} / \mathrm{min}$. 每分 析完一个样品, 以 $10 \% \mathrm{~B}, 0.2 \mathrm{~mL} / \mathrm{min}$ 的流速冲洗色 谱柱 15 min. (2) 质谱条件. 检测方法: $\operatorname{APCI}(+)$; 检 测模式: 选择性离子检测(SIM). GDGTs 各化合物分 子离子流 $[\mathrm{M}+\mathrm{H}]^{+}(\mathrm{m} / \mathrm{z}, 1302,1300,1298,1296,1294$, 1292, 1290, 1288, 1286, 1050, 1048, 1046, 1036, 1034, $1032 ， 1022 ， 1020 ， 1018)$, 其相对含量采用积分面积 比; 雾化气压 $60 \mathrm{psi}$; 干燥气 $\mathrm{N}_{2}$ 流速和温度分别为 5 $\mathrm{L} / \mathrm{min}$ 和 $200^{\circ} \mathrm{C}$; 雾化温度 $300^{\circ} \mathrm{C}$; 毛细管电压 $2500 \mathrm{~V}$; 电晕电流 $5 \mu \mathrm{A}$.

采用 Weijers 等人 ${ }^{[9]}$ 的积分方法和 Huguet 等 人 ${ }^{[27]}$ 定量方法对各个 GDGTs 化合物进行定量. 各指 标计算公式 ${ }^{[9]}$ 如下:

$$
\begin{gathered}
\mathrm{MBT}=([\mathrm{Ia}]+[\mathrm{Ib}]+[\mathrm{Ic}]) /(([\mathrm{Ia}]+[\mathrm{Ib}]+[\mathrm{Ic}]) \\
+([\mathrm{IIa}]+[\mathrm{IIl}]+[\mathrm{IIc}])+([\mathrm{III}]+[\mathrm{IIIb}]+[\mathrm{IIIc}])), \\
\mathrm{CBT}=-\log \left(\frac{([\mathrm{Ib}]+[\mathrm{IIb}])}{([\mathrm{Ia}]+[\mathrm{IIa}])}\right), \\
\mathrm{CBT}=3.33-0.38 \times \mathrm{pH}, \\
\mathrm{MBT}=0.122+0.187 \times \mathrm{CBT}+0.020 \times \text { MAAT. }
\end{gathered}
$$

\section{2 结果与讨论}

\section{1 剖面 GDGTs 的组成特征}

柱状样品中检测到了 5 种类异戊二烯类和 9 种支 链类 GDGTs. 检测出的类异戊二烯类 GDGTs 含量较 低, 为 $0.001 \sim 0.63 \mu \mathrm{g} / \mathrm{g}$ (图 3(a)), 占总 GDGTs 的 3\% 左右, 包括有 GDGT-0,1,2,3 和 Crenarchaeol(泉古菌 醇)化合物，没有检测到含 4 个环戊烷以上的类异戊 二烯 GDGTs, 其中 GDGT-0 为最主要化合物(占类异 戊二烯类 GDGTs 总量的 62\% 100\%). 同已发表的大 部分土壤、泥炭样品具有一定的相似性 ${ }^{[9,28,29]}$.

样品中支链 GDGTs 含量为 $1.8 \sim 20.3 \mu \mathrm{g} / \mathrm{g}$, 占总 GDGTs 含量的 96\% 100\%(图 3(b)), 主要包括 I, II, III 3 类化合物(表 1), 其中 GDGT- II 含量最高, I 次 之, III 含量最少; 并且样品中不含环戊烷的 a 类化合 物含量最高, 含有 1 个环戊烷的 $\mathrm{b}$ 类次之, 含有 2 个 环戊烷的 $\mathrm{c}$ 类含量最低. 支链 GDGTs 最早发现于泥 炭中 ${ }^{[30]}$, Weijers 等人 ${ }^{[14]}$ 研究发现支链 GDGTs 和细菌 
表 1 泥炭钻孔中支链 GDGTs 剖面变化 ${ }^{a)}$

\begin{tabular}{|c|c|c|c|c|c|c|c|c|c|c|c|c|}
\hline \multirow{2}{*}{ 样品 } & \multirow{2}{*}{ 采样深度 (cm) } & \multicolumn{9}{|c|}{ 单位质量各 GDGTs 含量 $\left(\mu \mathrm{g} \mathrm{g}^{-1}\right)$} & \multirow{2}{*}{ MBT } & \multirow{2}{*}{ CBT } \\
\hline & & Ic & $\mathrm{Ib}$ & Ia & IIc & $\mathrm{IIb}$ & Ia & IIIc & $\mathrm{IIIb}$ & IIIa & & \\
\hline HYS2-01 & 24.75 & 0.274 & 1.812 & 3.137 & 0.175 & 0.674 & 7.649 & - & - & 2.704 & 0.318 & 0.637 \\
\hline HYS2-02 & 24.25 & 0.136 & 0.753 & 1.404 & 0.067 & 0.278 & 3.406 & - & - & 1.075 & 0.322 & 0.669 \\
\hline HYS2-03 & 23.75 & 0.171 & 0.948 & 1.806 & 0.092 & 0.357 & 4.152 & - & - & 1.455 & 0.326 & 0.659 \\
\hline HYS2-04 & 23.25 & 0.276 & 1.266 & 2.855 & 0.148 & 0.613 & 6.620 & - & - & 2.260 & 0.313 & 0.703 \\
\hline HYS2-05 & 22.75 & 0.087 & 0.444 & 0.992 & 0.050 & 0.177 & 2.195 & - & - & 0.718 & 0.327 & 0.711 \\
\hline HYS2-06 & 22.25 & 0.058 & 0.263 & 0.583 & 0.029 & 0.124 & 1.284 & - & - & 0.467 & 0.322 & 0.684 \\
\hline HYS2-07 & 21.75 & 0.191 & 0.964 & 1.970 & 0.099 & 0.424 & 4.204 & - & - & 1.429 & 0.337 & 0.648 \\
\hline HYS2-08 & 21.25 & 0.260 & 1.382 & 2.880 & 0.141 & 0.606 & 6.562 & - & - & 2.090 & 0.325 & 0.677 \\
\hline HYS2-09 & 20.75 & 0.067 & 0.314 & 0.768 & 0.036 & 0.148 & 1.741 & - & - & 0.576 & 0.315 & 0.735 \\
\hline HYS2-10 & 20.25 & 0.126 & 0.592 & 1.326 & 0.055 & 0.264 & 2.959 & - & - & 0.958 & 0.326 & 0.699 \\
\hline HYS2-11 & 19.75 & 0.122 & 0.663 & 1.274 & 0.072 & 0.253 & 3.047 & - & - & 1.025 & 0.319 & 0.674 \\
\hline HYS2-12 & 19.25 & 0.052 & 0.279 & 0.572 & 0.028 & 0.125 & 1.315 & - & - & 0.419 & 0.323 & 0.670 \\
\hline HYS2-13 & 18.75 & 0.233 & 1.067 & 2.402 & 0.109 & 0.532 & 5.556 & - & - & 1.791 & 0.317 & 0.697 \\
\hline HYS2-14 & 18.25 & 0.198 & 1.137 & 2.287 & 0.104 & 0.480 & 5.863 & - & - & 1.948 & 0.301 & 0.702 \\
\hline HYS2-15 & 17.75 & 0.117 & 0.692 & 1.323 & 0.059 & 0.291 & 3.108 & - & - & 1.023 & 0.322 & 0.654 \\
\hline HYS2-17 & 16.75 & 0.142 & 0.940 & 1.962 & 0.085 & 0.457 & 4.901 & - & - & 1.498 & 0.305 & 0.692 \\
\hline HYS2-18 & 16.25 & 0.093 & 0.557 & 1.164 & 0.050 & 0.299 & 2.897 & - & - & 0.908 & 0.304 & 0.676 \\
\hline HYS2-19 & 15.75 & 0.100 & 0.574 & 1.192 & 0.033 & 0.314 & 3.169 & - & - & 0.918 & 0.296 & 0.691 \\
\hline HYS2-20 & 15.25 & 0.050 & 0.374 & 0.781 & 0.030 & 0.236 & 1.968 & - & - & 0.596 & 0.299 & 0.653 \\
\hline HYS2-21 & 14.75 & 0.065 & 0.448 & 0.887 & 0.036 & 0.280 & 2.268 & - & - & 0.697 & 0.299 & 0.637 \\
\hline HYS2-22 & 14.25 & 0.027 & 0.175 & 0.354 & 0.011 & 0.102 & 0.862 & - & - & 0.283 & 0.307 & 0.642 \\
\hline HYS2-23 & 13.75 & 0.121 & 0.821 & 1.575 & 0.044 & 0.507 & 3.983 & - & - & 1.214 & 0.305 & 0.621 \\
\hline HYS2-24 & 13.25 & 0.115 & 0.917 & 1.775 & 0.044 & 0.596 & 4.602 & - & 0.030 & 1.434 & 0.295 & 0.625 \\
\hline HYS2-25 & 12.75 & 0.063 & 0.559 & 1.040 & 0.029 & 0.329 & 2.537 & - & - & 0.866 & 0.307 & 0.605 \\
\hline HYS2-26 & 12.25 & 0.066 & 0.565 & 1.117 & 0.036 & 0.345 & 2.969 & - & - & 0.964 & 0.288 & 0.652 \\
\hline HYS2-27 & 11.75 & 0.100 & 0.884 & 1.710 & 0.062 & 0.568 & 4.523 & - & 0.026 & 1.456 & 0.289 & 0.633 \\
\hline HYS2-28 & 11.25 & 0.057 & 0.462 & 0.925 & 0.026 & 0.289 & 2.508 & - & 0.013 & 0.797 & 0.284 & 0.660 \\
\hline HYS2-29 & 10.75 & 0.117 & 0.870 & 1.762 & 0.037 & 0.580 & 4.680 & - & 0.025 & 1.509 & 0.287 & 0.648 \\
\hline HYS2-30 & 10.25 & 0.049 & 0.407 & 0.815 & 0.017 & 0.249 & 2.282 & - & 0.013 & 0.682 & 0.282 & 0.674 \\
\hline HYS2-31 & 9.75 & 0.048 & 0.393 & 0.913 & 0.015 & 0.250 & 2.309 & - & 0.011 & 0.711 & 0.291 & 0.700 \\
\hline HYS2-32 & 9.25 & 0.091 & 0.857 & 1.781 & 0.029 & 0.468 & 4.526 & 0.014 & 0.016 & 1.365 & 0.298 & 0.678 \\
\hline HYS2-34 & 8.25 & 0.116 & 0.951 & 2.367 & 0.032 & 0.615 & 5.648 & - & 0.023 & 1.701 & 0.300 & 0.709 \\
\hline HYS2-35 & 7.75 & 0.140 & 1.301 & 3.211 & 0.069 & 0.750 & 7.784 & - & 0.032 & 2.320 & 0.298 & 0.729 \\
\hline HYS2-36 & 7.25 & 0.165 & 1.631 & 4.049 & 0.056 & 1.025 & 10.104 & 0.070 & 0.043 & 3.140 & 0.288 & 0.727 \\
\hline HYS2-37 & 6.75 & 0.131 & 1.262 & 3.659 & 0.033 & 0.767 & 9.375 & 0.023 & 0.040 & 2.944 & 0.277 & 0.808 \\
\hline HYS2-38 & 6.25 & 0.053 & 0.697 & 2.015 & 0.017 & 0.412 & 4.815 & 0.009 & 0.017 & 1.565 & 0.288 & 0.790 \\
\hline HYS2-39 & 5.75 & 0.085 & 0.977 & 2.991 & 0.028 & 0.557 & 7.731 & 0.011 & 0.031 & 2.503 & 0.272 & 0.844 \\
\hline HYS2-40 & 5.25 & 0.089 & 0.728 & 1.627 & 0.028 & 0.462 & 4.133 & - & 0.015 & 1.268 & 0.293 & 0.685 \\
\hline HYS2-41 & 4.75 & 0.054 & 0.579 & 1.862 & 0.012 & 0.363 & 5.040 & 0.013 & 0.020 & 1.636 & 0.260 & 0.865 \\
\hline HYS2-42 & 4.25 & 0.036 & 0.478 & 1.813 & 0.006 & 0.314 & 4.567 & - & 0.013 & 1.460 & 0.268 & 0.907 \\
\hline HYS2-43 & 3.75 & 0.031 & 0.444 & 1.454 & 0.009 & 0.328 & 3.701 & - & 0.012 & 1.097 & 0.273 & 0.825 \\
\hline HYS2-44 & 3.25 & 0.042 & 0.478 & 1.502 & - & 0.310 & 3.583 & - & 0.014 & 1.176 & 0.285 & 0.810 \\
\hline HYS2-45 & 2.75 & 0.064 & 0.580 & 1.765 & - & 0.465 & 4.522 & - & 0.025 & 1.359 & 0.274 & 0.779 \\
\hline HYS2-46 & 2.25 & 0.028 & 0.342 & 0.948 & 0.010 & 0.275 & 2.263 & - & 0.015 & 0.668 & 0.290 & 0.717 \\
\hline HYS2-47 & 1.75 & 0.054 & 0.656 & 1.815 & 0.032 & 0.500 & 4.283 & - & 0.024 & 1.207 & 0.295 & 0.722 \\
\hline HYS2-48 & 1.25 & 0.042 & 0.473 & 1.197 & 0.013 & 0.406 & 2.537 & - & 0.018 & 0.705 & 0.318 & 0.628 \\
\hline HYS2-49 & 0.75 & 0.028 & 0.331 & 0.896 & - & 0.351 & 1.926 & - & 0.022 & 0.534 & 0.307 & 0.617 \\
\hline HYS2-50 & 0.25 & 0.036 & 0.474 & 1.090 & 0.022 & 0.486 & 2.586 & 0.009 & 0.036 & 0.751 & 0.291 & 0.583 \\
\hline
\end{tabular}

a) “-”为低于仪器检测限

合成的甘油基团具有相同的立体结构，推测支链类 分布在土壤 ${ }^{[31,32]}$ 、泥炭中 ${ }^{[31]}$, 以及湖泊和近海沉积物 GDGTs 可能来源于某种厌氧细菌. 支链 GDGTs 广泛 中 ${ }^{[31,33]}$. 最初认为湖泊与近海沉积物中支链 GDGTs 


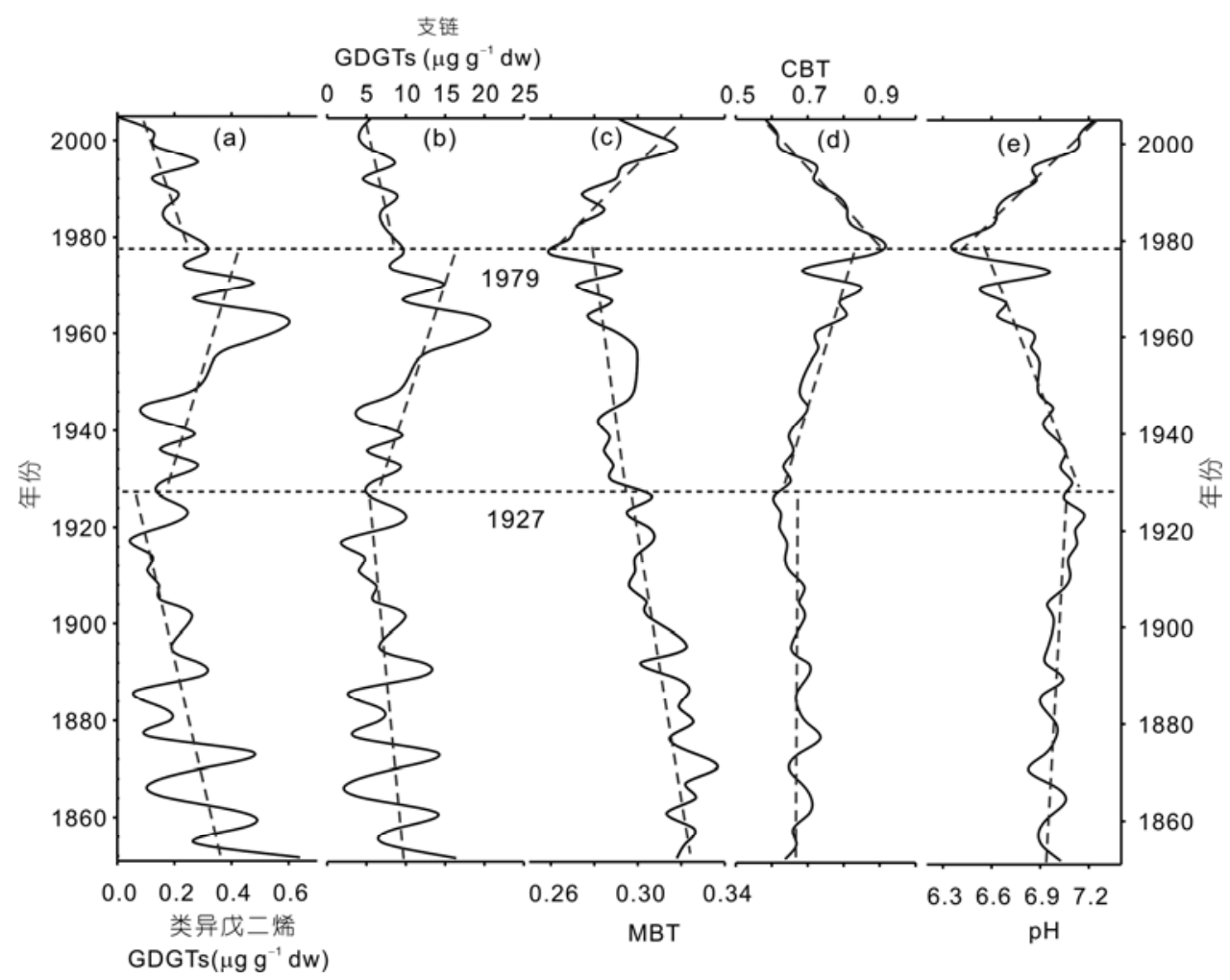

图 3 类异戊二烯类 $(\mathrm{a})$ 、支链类 GDGTs 总量 $(b) 、 M B T(c) 、 C B T(d)$ 和 $\mathrm{pH}(\mathrm{e})$ 的剖面变化

是由地表径流和河流搬运的陆源土壤所带人的 ${ }^{[34,35]}$, 但新近的研究发现在河口或湖泊等水生环境也能内 源产生支链 GDGTs ${ }^{[17,36 \sim 38]}$

\section{$2.2 \mathrm{pH}$ 和 MAAT 的剖面变化}

近年来, 许多学者利用近海海洋沉积中支链 GDGTs, 根据 Weijers 等人 ${ }^{[9]}$ 提出的 MBT/CBT 经验 公式进行了一些陆地 MAAT 和 $\mathrm{pH}$ 重建研究工作, 包 括对刚果盆地末次冰期和间冰期 ${ }^{[16]}$, 北冰洋地区古 新世-始新世最热事件(PETM) 时期 ${ }^{[15]}$ 以及格陵兰岛 渐新世-始新世的 MAAT 和 $\mathrm{pH}$ 的重建 ${ }^{[11]}$ 等; 另外, 利用湖泊沉积中支链 GDGTs 来重建古气候信息也得 到了一些应用, 例如, Zink 等人 ${ }^{[39]}$ 通过对比新西兰岛 上湖泊沉积物中支链 GDGTs 分布和记录温度, 发现 将 MBT 指标应用到湖泊沉积中是一种重建陆地古温 度的良好工具, Tyler 等人 ${ }^{[36]}$ 首次利用 Lochnagar 湖泊 沉积中支链 GDGTs 分布重建了苏格兰地区近 400 年 的 $\mathrm{pH}$ 和 MAAT 变化. Weijers 等人 ${ }^{[9]}$ 提出的 MBT/ CBT 指标在近海、湖泊沉积中都得到了较好应用, 作 者首次将 MBT/CBT 指标应用到泥炭沉积中, 讨论了 指标在泥炭沉积中的适用性和应用潜力.
本研究中计算的 $\mathrm{CBT}$ 和 $\mathrm{MBT}$ 指数分别为 0.583 0.865 和 0.260 0.337(图 3(d) 和(c), 表 1). 根据 式(2)和(3)计算的若尔盖草原泥炭近 150 年来 $\mathrm{pH}$ 为 6.4 7.2(图 3(e)). 采用经典方法 1:2.5(泥炭: 纯水, $\mathrm{m}: \mathrm{v})^{[17]}$ 混匀、离心, 测量上清液 $\mathrm{pH}$ 代表泥炭 $\mathrm{pH}$. 利 用此种方法测量的泥炭表层 $\mathrm{pH}$ 为 6.9 , 较计算的表 层 $\mathrm{pH}(7.1)$ 稍低. 若尔盖地区近 150 年来 $\mathrm{pH}$ 大致存在 经历了 3 个变化阶段: 1851 1927 年, 土壤泥炭 $\mathrm{pH}$ 为 7.0, 基本保持稳定, 与 1930 年以前这个区域为无人 或半无人的原始沼泽景观相对应 ${ }^{[40]} ; 1927$ 1979 年, 泥炭 $\mathrm{pH}$ 从 7.0 降低到了 6.4 , 可能是由于 20 世纪 20 年代起, 川西北森林被大规模开发 ${ }^{[41]}$, 毁林开荒、发 展“火地”等行为造成大量腐殖质(以胡敏酸和富里酸 为主要成分)的沉积; 1979 年至今, $\mathrm{pH}$ 从 6.4 到 7.2 大 幅升高 0.8 . 近 30 年以来, 泥炭 $\mathrm{pH}$ 变化幅度较大且 逐渐升高, 可能和人类活动的干扰致使腐植酸含量 的减少有关 ${ }^{[42,43]}$.

根据算式(4)计算的 MAAT 为 $-0.4 \sim 4.7^{\circ} \mathrm{C}$, 其变 化也大致经历了 3 个阶段(图 4(d)): 1851 1927 年, MAAT 为 $2.8 \sim 3.8^{\circ} \mathrm{C}$, 温度变化幅度相对较小 (缓慢降 低约 $\left.1{ }^{\circ} \mathrm{C}\right) ; 1927 \sim 1979$ 年, MAAT 为 $-1.2 \sim 2.4^{\circ} \mathrm{C}$, 以 
$0.05^{\circ} \mathrm{C} /$ 年的速率降低了 $2.5^{\circ} \mathrm{C} ; 1979$ 至今, MAAT 为 $-1.2 \sim 3.9^{\circ} \mathrm{C}$, 以 $0.17^{\circ} \mathrm{C} /$ 年的速率升高了 $5^{\circ} \mathrm{C}$. 计算的 温度在一些时间段(1945 年以来)和中国年平均气温 具有相同的变化趋势, 但由于红原地区位于四川西 北部, 青藏高原东部边缘, 特殊的地理位置使其既受 青藏高原环流系统的影响, 又受东亚季风和印度季 风的影响, 致使红原气候具有很强的地域性 ${ }^{[20,44]}$. 比 如，1910 1940 年, 全国年平均气温有明显的增温趋 势 ${ }^{[45,46]}$ ，而该地区没有明显的温度变化，宋慧明等 人 $^{[47]}$ 用树木年轮推测九寨沟冬半年平均最低温度在 此阶段也没有表现出明显的增温趋势, 表明本地区 与中国其他地区以及全球增温趋势不完全一致 ${ }^{[45]}$.

1957 2001 年间, 利用 MBT/CBT 计算平均气温 值为 $1.0^{\circ} \mathrm{C}$, 与若尔盖气象站记录的 45 年平均气温 $\left(0.9^{\circ} \mathrm{C} \text { ) 非常接近(图 4(a) (c) }\right)^{[48]}$. 通过相关性分析, 利用 CBT/MBT 计算的温度与记录的 3 年平均、冬季 平均和夏季平均温度进行相关分析(图 4(e) (g)), 计
算温度和年平均温度有一定的相关性, $R^{2}=0.324$ $(P<0.05, N=15)$; 计算温度和冬季平均温度、夏季平 均温度相关性相对较差 $(P<0.05, N=15)$. 相关性比较 低可能由于恒定比活度模式 ${ }^{210} \mathrm{~Pb}$ 定年假设泥炭具有 恒定的沉积速率等, 致使计算的 3 年平均温度与实测 的 3 年平均温度在时间上不能完全吻合造成的. 同时 计算的 1957 2001 年间平均温度变化幅度 $\left(5.1^{\circ} \mathrm{C}\right)$ 比 实测温度变化幅度 $\left(1.4^{\circ} \mathrm{C}\right)$ 大. 通过对 Weijers 等人 ${ }^{[9]}$ 研究的全球 112 个样品计算, 发现 MAAT $<10^{\circ} \mathrm{C}$ 的采 样点和 MAAT $>10^{\circ} \mathrm{C}$ 的采样点样品计算温度和实测温 度间差值的平均值、标准偏差分别为 $-3.78^{\circ} \mathrm{C}$ 和 5.95 以及 $3.42^{\circ} \mathrm{C}$ 和 4.36 , 说明高纬度和高海拔等低温地区 计算 MAAT 值较实测温度高 ${ }^{[17,33]}$, 且和实测值相比 离散程度较高; 在低纬度高温地区计算 MAAT 较实 测温度值低 ${ }^{[10]}$, 且和实测值相比离散程度较低. 所 以由于全球不同地区土壤具有不同动力学过程 ${ }^{[10,17,33]}$ 或存在影响支链 GDGTs 合成随纬度变化的
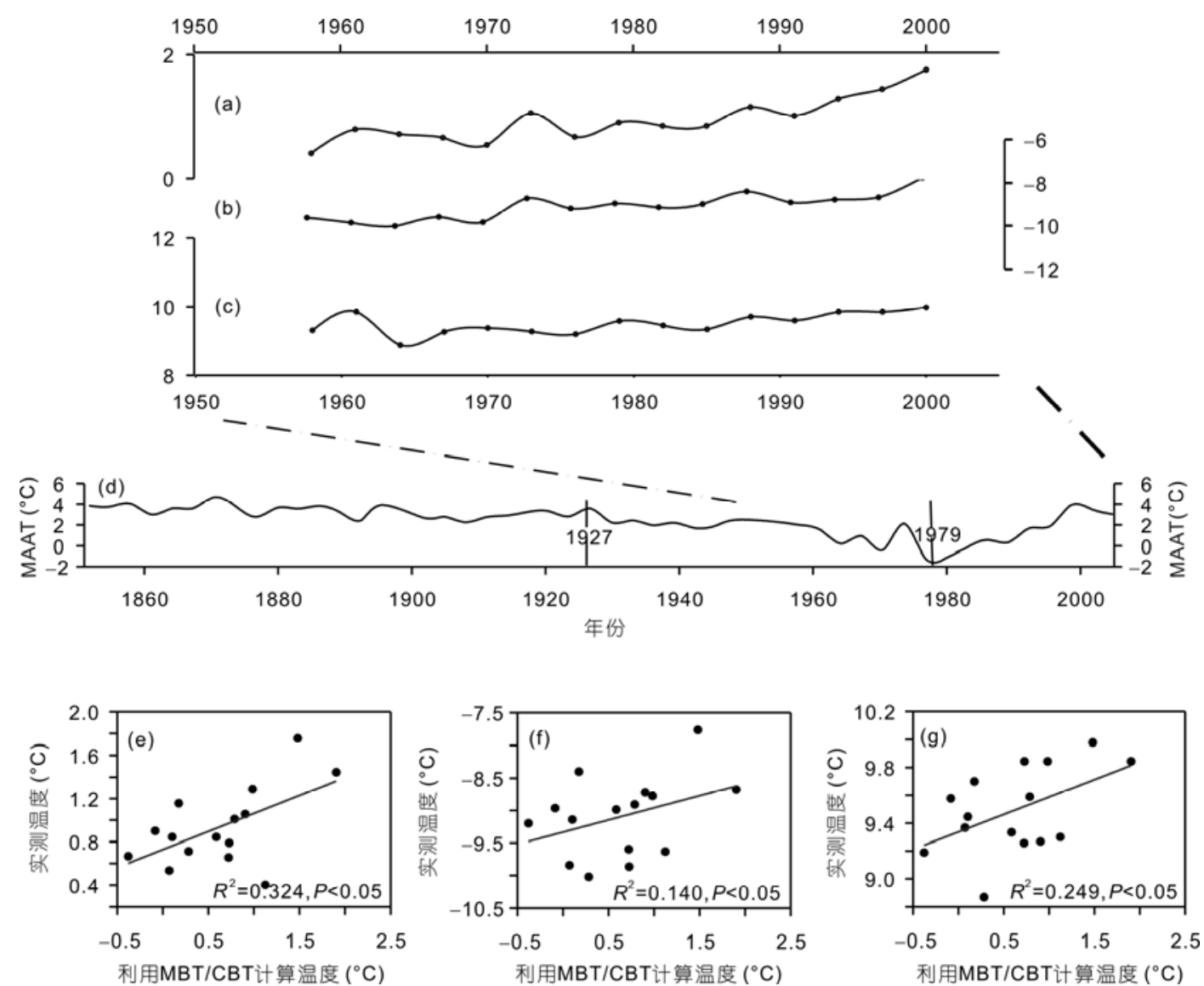

图 4 若尔盖气象站记录 ${ }^{[48]}$ 的 3 年年平均气温 $(a)$ 、冬季平均气温 $(b)$ 、夏季平均气温 $(c)$ 与利用 MBT/CBT 指数计算的大气 温度 $(\mathrm{d})$ 对比以及利用 MBT/CBT 指数计算温度与 3 年年平均 $(\mathrm{e})$ 、冬季平均 $(\mathrm{f})$ 和夏季平均记录温度 $(\mathrm{g})$ 之间的相关性 
因素 ${ }^{[36]}$, 在不同区域可能需要建立更精确的 MAAT 计算经验公式.

\section{3 结论}

利用四川红原泥炭中支链四醚膜类脂 (GDGTs) 相关 $\mathrm{pH}$ 指标 CBT 和温度指标 MBT/CBT, 重建了若 尔盖地区近 150 年来泥炭 $\mathrm{pH}$ 和 MAAT 变化, 其大致
存在 3 个变化阶段. 近 45 年来, 计算温度变化幅度 $\left(5.1^{\circ} \mathrm{C}\right)$ 比实测温度变化幅度 $\left(1.4^{\circ} \mathrm{C}\right)$ 大, 可能和当地 的土壤动力学特征有关. 但是气候资料记录的近 45 年来平均温度与计算平均温度相近, 且该地区近 150 年来计算温度和树轮记录温度具有相似的变化趋势. 说明泥炭沉积中 GDGTs 相关指数在高分辨重建陆地 古环境的适用性和应用潜力.

\section{参考文献}

1 Blackford. Palaeoclimatic records from peat bogs. Trends Ecol Evol, 2000, 15: 193-198

2 Ménot-Combes G, Burns S J, Leuenberger M. Variations of ${ }^{18} \mathrm{O} /{ }^{16} \mathrm{O}$ in plants from temperate peat bogs(Switzerland): Implications for paleoclimatic studies. Earth Planet Sci Lett, 2002, 202: 419-434

3 Hong Y T, Wang Z G, Jiang H B. A 6000-year record of changes in drought and precipitation in northeastern China based on a ${ }^{13} \mathrm{C}$ time series from peat cellulose. Earth Planet Sci Lett, 2001, 185: 111-119

4 李辉, 王升忠, 冷雪天. 泥炭沼泽有机地球化学研究进展. 矿物岩石地球化学通报, 2004, 23: 172-178

5 陶发祥, 刘广深. 地质档案中的纤维素提取. 矿物岩石地球化学通报, 1995, 14: 245-246

6 林庆华, 洪业汤, 朱咏煊, 等. 中国典型泥炭区现代植物的碳、氧同位素组成及在古环境研究中的意义. 矿物岩石地球化学通报, 2004, 20: 93-97

7 徐海, 洪业汤, 林庆华. 红原泥炭纤维素氧同位素指示的距今 $6 \mathrm{ka}$ 温度变化. 科学通报, 2002, 47: 1181-1186

8 郑艳红，周卫健，谢树成. 若尔盖高原全新世气候序列的类脂分子化石记录. 第四纪研究, 2007, 27: 108-113

9 Weijers J W H, Schouten S, van den Donker J C, et al. Environmental controls on bacterial tetraether membrane lipid distribution in soils. Geochim Cosmochim Acta, 2007, 71: 703-713

10 Sinninghe Damsté J S, Ossebaar J, Schouten S. Altitudinal shifts in the branched tetraether lipid distribution in soil from Mt. Kilimanjaro (Tanzania): Implications for the MBT/CBT continental palaeothermometer. Org Geochem, 2008, 39: 1072-1076

11 Schouten S, Eldrett J, Greenwood D R, et al. Onset of long-term cooling of Greenland near the Eocene-Oligocene boundary as revealed by branched tetraether lipids. Geology, 2008, 36: 147-150

12 Peterse F, Schouten S, van der Meer J, et al. Distribution of branched tetraether lipids in geothermally heated soils: Implications for the MBT/CBT temperature proxy. Org geochem, 2009, 40: 201-205

13 Schouten S, Hopmans E C, Schefuß E, et al. Distributional variations in marine crenarchaeotal membrance lipids: A new tool for reconstructing ancient sea water temperatures? Earth Planet Sci Lett, 2002, 204: 265-274

14 Weijers J W H, Schouten S, Hopmans E C, et al. Membrane lipids of mesophilic anaerobic bacteria thriving in peats have typical archaeal traits. Environ Microbiol, 2006, 8: 648-657

15 Weijers J W H, Schefuß E, Schouten S, et al. Coupled thermal and hydrological evolution of tropical Africa over the last deglaciation. Science, 2007, 315: 1701-1704

16 Weijers J W H, Schouten S, Sluijs A. Warm arctic continents during the Palaeocene-Eocene thermal maximum. Earth Planet Sci Lett, 2007, 261: 230-238

17 Peterse F, Kim J H, Schouten S, et al. Constraints on the application of the MBT/CBT palaeothermometer at high latitude environments (Svalbard, Norway). Org Geochem, 2009, 40: 692-699

18 高俊琴, 欧阳华, 白军红. 若尔盖高寒湿地土壤活性有机碳垂直分布特征. 水土保持学报, 2006, 20: 76-80

19 王华, 洪业汤, 朱咏煊, 等. 红原泥炭腐殖化度记录的全新世气候变化. 地质地球化学, 2003, 31: 51-56

20 洪冰, 林庆华, 朱咏煊, 等. 红原泥炭苔草的碳同位素组成与全新世季风变化. 矿物岩石地球化学通报, 2003, 22: 99-103

21 万国江. ${ }^{137} \mathrm{Cs}$ 及 ${ }^{210} \mathrm{~Pb}_{\mathrm{ex}}$ 方法湖泊沉积计年研究新进展. 地球科学进展, 1995, 10: 188-192

22 张敬, 牟德海, 杜金洲, 等. 过剩 ${ }^{210} \mathrm{~Pb}$ 年代学的多种计算模式的比较研究. 海洋环境科学, 2008, 27: 370-375

23 吴敬禄, 李世杰, 王苏民，等. 若尔盖盆地兴措湖沉积记录揭示的近代气候与环境. 湖泊科学, 2000, 12: 291-296

24 Appleby P G, Nolan P J, Gifford D W, et al. ${ }^{210} \mathrm{~Pb}$ dating by low background gamma counting. Hydrobiologia, 1986, 143: 21-27

25 Hopmans E C, Schouten S, Pancost R D, et al. Analysis of intact tetrameter lipids in archaeal cell material and sediments by high performance liquid chromatography/atmospheric pressure chemical ionization mass spectrometry. Rapid Commun Mass Sp, 2000, 14: $585-589$ 
26 Schouten S, Huguet C, Hopmans E C, et al. Analytical methodology for TEX 86 paleothermometry by high-performance liquid chromatography/atmospheric pressure chemical ionization-mass spectrometry. Anal Chem, 2007, 79: 2940-2944

27 Huguet C, Hopmans E C, Febo-Ayala W, et al. An improved method to determine the absolute abundance of glycerol dibiphytanyl glycerol tetraether lipids. Org Geochem, 2007, 37: 1036-1041

28 Weijers J W H, Schouten S, van der Linden M, et al. Water table related variations in the abundance of intact archaeal membrane lipids in a Swedish peat bog. FEMS Microbiol Lett, 2004, 239: 51-56.

29 Weijers J W H, Schouten S, Spaargaren O C, et al. Occurrence and distribution of tetraether membrane lipids in soils: Implications for the use of the TEX $\mathrm{T}_{86}$ proxy and the BIT index. Org Geochem, 2006, 37: 1680-1693

30 Sinninghe Damsté J S, Hopmans E C, Richard D, et al. Newly discovered non-isoprenoid glycerol dialkyl glycerol tetraether lipids in sediments. Roy Soc Chem, 2000, 17: 1683-1684

31 Schouten S, Hopmans E C, Pancost R D, et al. Widespread occurrence of structurally diverse tetraether membrane lipids: Evidence for the ubiquitous presence of low-temperature relatives of hyperthermophiles. Proc Natl Acad Sci USA, 2000, 97: 14421-14426

32 Kim J H, Schouten S, Buscail R, et al. Origin and distribution of terrestrial organic matter in the NW Mediterranean (Gulf of Lions): Exploring the newly developed BIT index. Geochem Geophys Geosys, 2006, 7: 1-20

33 Rueda G, Rosell-Melé A, Escala M, et al. Comparison of instrumental and GDGT based estimates of sea surface and air temperatures from the Skagerak. Org Geochem, 2009, 40: 287-291

34 Hopmans E C, Weijers J W H, Schefu $\beta$ E, et al. A novel proxy for terrestrial organic matter in sediments based on branched and isoprenoid tetraether lipids. Earth Planet Sci Lett, 2004, 224: 107-116

35 Walsh E M, Ingalls A E, Keil R G. Sources and transport of terrestrial organic matter in Vancouver Island fjords and the Vancouver-Washington Margin: A multiproxy approach using $\delta^{13} \mathrm{C}_{\text {org }}$, lignin phenols, and the ether lipid BIT index. Limnol Oceanogr, 2008, 53: 1054-1063

36 Tyler J J, Nederbragt A J, Jones V J, et al. Assessing past temperature and soil $\mathrm{pH}$ estimates from bacterial tetraether membrane lipids: Evidence from the recent lake sediments of Lochnagar, Scotland. J Geophys Res, 2010, 115, doi: 10.1029/2009JG001109

37 Tierney J E, Russell J M. Distributions of branched GDGTs in a tropical lake system: implications for lacustrine application of the MBT/CBT paleoproxy. Org Geochem, 2009, 40: 1032-1036

38 Sinninghe Damsté J S, Ossebaar J, Abbas B, et al. Fluxes and distribution of tetraether lipids in an equatorial African lake: Constraints on the application of the TEX 86 palaeothermometer and BIT index in lacustrine settings. Geochim Cosmochim Acta, 2009, 73: 4232-4249

39 Zink K G, Vandergoes M J, Mangelsdorf K, et al. Application of bacterial glycerol dialkyl glycerol tetraethers (GDGTs) to develop modern and past temperature estimates from New Zealand lakes. Org Geochem, 2010, 41: 1060-1066

40 郭杰, 李国平. 若尔盖气候变化及其对湿地退化的影响. 高原气象, 2007, 26: 422-428

41 张保见. 近代(1840-1949)川西北的森林开发与破坏述论. 康定民族师范高等专科学校学报, 2008, 17: 40-46

42 杨永兴, 王世岩. 人类活动干扰对若尔盖高原沼泽土、泥炭土资源影响的研究. 资源科学, 2001, 23: 37-41

43 王红, 吴凯. 红原县沼泽草地现状及保护建议. 草业与畜牧, 2009, 3: 37-38

44 王燕, 赵志中, 乔彦松, 等. 川北若尔盖高原红原泥炭剖面狍粉记录的晚冰期以来古气候古环境的演变. 地质通报, 2006, 25: $827-832$

45 丁一汇, 戴晓苏. 中国近百年来的温度变化. 气象, 1994, 12: 19-27

46 王绍武. 全球气候变暖与未来发展趋势. 第四纪研究, 1991, 3: 269-276

47 宋慧明, 刘禹, 倪万眉, 等. 以树轮宽度重建九寨沟 1750 年以来冬半年平均最低温度. 第四纪研究, 2007, 27: 486-491

48 王燕, 赵志中, 乔彦松, 等. 若尔盖 45 年来的气候变化特征及其对当地生态环境的影响. 地质力学学报, 2005, 11: 328-333 